\title{
The effect of omalizumab treatment on IgE and other immunoglobulin levels in patients with chronic spontaneous urticaria and its association with treatment response
}

\author{
Songül Çildağ, Taşkın Şentürk \\ Department of Allergy and Clinical Immunology, Adnan Menderes University, Aydın, Turkey \\ Adv Dermatol Allergol 2018; XXXV (5): 516-519 \\ DOI: https://doi.org/10.5114/ada.2017.71422
}

\begin{abstract}
Introduction: Suppression of free immunoglobulin E (IgE) levels and an increase in total lgE levels are observed during omalizumab treatment. However, whether omalizumab has any effect on other immunoglobulins is unknown. Aim: To investigate the effect of omalizumab treatment on serum IgE and other immunoglobulins, and demonstrate any association with response to treatment in patients with chronic spontaneous urticaria (CSU).

Material and methods: The study included 41 patients diagnosed with CSU. Baseline and post-12-week-treatment total IgE, IgA, IgM, and IgG levels and blood eosinophil, neutrophil, lymphocyte and platelet levels were compared. Patients were grouped based on weekly urticaria activity score (UAS-7) responses and these parameters were compared.

Results: There was a significant increase in baseline and post-12-week-treatment total IgE levels, while there was no significant difference in other immunoglobulin levels. A significant reduction was found in neutrophil counts after the treatment, whereas there was no significant difference in eosinophil, lymphocyte and platelet levels. There was no difference in these parameters between groups with complete response and without complete response. Conclusions: Omalizumab treatment can also be used in patients with immunoglobulin deficiency. Due to the observed reduction in neutrophil counts after the treatment, patients must be closely followed for whole blood parameters.
\end{abstract}

Key words: chronic urticaria, immunoglobulin, omalizumab.

\section{Introduction}

Chronic spontaneous urticaria (CSU) is a disease characterized by itching, wheals and/or angioedema lasting longer than 6 weeks with no triggers. Baseline and first-line therapy in CSU treatment is non-sedated $\mathrm{H}_{1}$-antihistamine therapy, and increasing the dose up to 4 times in second-line therapy is recommended. Omalizumab, cyclosporine and leukotriene antagonists are included in third-line therapy for refractory cases [1].

Omalizumab is a human monoclonal antibody in the form of IgG1 which is designed against IgE. Omalizumab blocks the binding of IgE to FceRI on the surface of mast cells and basophils by binding free IgE from Fce3 fragments [2]. Thereby, FceRI on the surface of basophils and mast cells undergo downregulation. Omalizumab increases total lgE levels, while decreasing free lgE levels by more than $95 \%$ [3]. The increase in total IgE levels can generally be explained by the prolongation of the halflife of IgE, which has a half-life of 2-3 days, by binding to omalizumab of IgG1 structure, which has a half-life of 26 days $[4,5]$. An increase in total IgE levels is known to continue for more than one year after termination of the treatment.

A decrease in inflammatory mediators with omalizumab in allergic diseases requires a 95\% reduction in IgE levels [6, 7]. Therefore, an omalizumab dose in patients with asthma is determined based on IgE level and body weight [8]. However, since CSU is not a classic allergen-driven disease, a fixed dose of omalizumab is used [9-11].

Address for correspondence: Songül Çildağ, Department of Allergy and Clinical Immunology, Adnan Menderes University, Aydın 09100 , Turkey, phone: +90 05065092753, fax: +90 25621201 46, e-mail: songulcildag@yahoo.com Received: 13.06.2017, accepted: 11.09.2017. 
The effect of omalizumab treatment on total serum IgE levels is well-known. However, we did not find any studies demonstrating the effect on other immunoglobulins.

\section{Aim}

The aim of this study is to investigate the effect of omalizumab treatment on peripheral blood lgE and other immunoglobulins and demonstrate any association with response to treatment.

\section{Material and methods}

We retrospectively analyzed 41 patients who started omalizumab treatment for refractory CSU. For this study, an approval was obtained from the Ethics Committee for Non-invasive Clinical Studies at the Adnan Menderes University School of Medicine (No. 2017/1083). The subcutaneous omalizumab dose administered to the patients was 300 mg once a month. Total IgE, A, M, G, disease activity by using the weekly urticaria activity score (UAS-7) pretreatment (baseline) and post-12-week treatment with omalizumab, were recorded. Also blood neutrophil, lymphocyte, eosinophil and platelet counts were recorded.

The UAS-7 is a calculated patient reported outcome measure derived by summing the score for the number of wheals and intensity of pruritus ( 0 : none, 1: mild, 2: moderate, 3: severe) per day for 7 consecutive days.

In CSU, a "complete response" to omalizumab was defined as a reduction of $90 \%$ or more in the UAS-7, a "significant improvement" as a reduction in the UAS-7 of $90 \%-30 \%$ and "no significant improvement" as less than 30\% reduction in the UAS-7 [12].

Total serum IgE, IgA, IgM, and IgG levels were measured using the turbidimetric method (Tokyo Boeki Pres- tige 24i, Japan). Blood neutrophil, lymphocyte, eosinophil and platelet counts were measured using Sysmex XN1000 hematology analyzer.

\section{Statistical analysis}

Statistical analysis was performed with SPSS 21.0. All data were analyzed using Kolmogorov-Smirnov test for normal distribution. Descriptive statistics were reported using mean \pm standard deviation for data conforming to normal distribution and median and $25-75^{\text {th }}$ percentiles for data not conforming to normal distribution. For statistical analysis, Wilcoxon and Mann Whitney $U$ tests were used for dependent groups. Type 1 error level was considered 0.05 .

\section{Results}

A total of 41 patients, 21 female and 20 male, were enrolled in the study. Mean age was $45.65 \pm 11.79$ years, mean duration of disease was $70.78 \pm 59.0$ months. After 12 weeks of omalizumab treatment, 17 (41.4\%) patients had a complete response, 21 (51.2\%) patients had a significant improvement, and 3 (7.31\%) patients did not have any significant improvement based on UAS-7. When pre- and post-12-week treatment immunoglobulin levels were compared, there was no difference in IgG, IgA or IgM whereas there was a significant difference in IgE levels $(p<0.001)$. Also, there was no difference in blood eosinophil, lymphocyte or platelet levels whereas a significant difference was observed in neutrophil levels $(p<0.001)$ (Table 1).

No significant differences were observed in baseline IgE, IgA, IgM, or IgG levels when patients were divided into two groups as 17 (41.4\%) patients with a complete response and 24 (58.6\%) patients without complete response ( $p=0.48, p=0.90, p=0.58, p=0.38$ ). Again,

Table 1. Comparison of total IgE, IgA, IgM, IgG and serum eosinophil, neutrophil, lymphocyte, platelet levels before and after 12 weeks' omalizumab treatment in all patients

\begin{tabular}{|c|c|c|c|}
\hline \multirow[t]{2}{*}{ Parameter } & \multicolumn{2}{|c|}{ Omalizumab therapy } & \multirow[t]{2}{*}{$P$-value } \\
\hline & $\begin{array}{c}\text { Baseline } \\
\text { Median and 25-75P }\end{array}$ & $\begin{array}{c}\text { After } 12 \text { weeks } \\
\text { Median and } 25-75 P\end{array}$ & \\
\hline IgE (N: 1-100 mg/dl) & $152(42-444)$ & 386 (159-1282) & $<0.001$ \\
\hline $\operatorname{lgA}(\mathrm{N}:$ 50-400 mg/dl) & $185(147-248)$ & 189(153-281) & 0.118 \\
\hline $\operatorname{lgM}(\mathrm{N}: 50-250 \mathrm{mg} / \mathrm{dl})$ & $101(75-132)$ & $105(66-140)$ & 0.123 \\
\hline IgG (N: 600-1500 mg/dl) & 1106 (941-1219) & 1108 (1033-1309) & 0.067 \\
\hline Eosinophil (N: 40-540/mm³) & $160(80-245)$ & $140(83-270)$ & 0.468 \\
\hline Neutrophil (N: 2100-6100/mm³) & $5040(3710-6200)$ & $3910(2955-5370)$ & $<0.001$ \\
\hline Lymphocyte (N: 1320-3570/mm³) & $2300(1635-2835)$ & $2450(1845-2810)$ & 0.154 \\
\hline Platelet (N: $150-340 / \mathrm{mm}^{3}$ ) & $271(220-322)$ & $268(225-305)$ & 0.206 \\
\hline UAS-7 & $27(22-32)$ & $7(0-12)$ & $<0.001$ \\
\hline
\end{tabular}

$N-$ normally, $25-75 P-25^{\text {th }}$ and $75^{\text {th }}$ percentiles. 
there was no difference in baseline eosinophil, neutrophil, lymphocyte or platelet levels when the two groups were compared ( $p=0.42, p=0.23, p=0.13, p=0.50$ ).

\section{Discussion}

Omalizumab binds to circulating free IgE and thereby inhibits binding of IgE to FCERI. Since it does not bind IgE on the cell surface, it does not directly affect mast cells and basophils $[13,14]$. A decrease in the circulating free IgE levels results in reduction of the FceRI receptor count on the surface of mast cells, basophils and other antigen presenting cells [15-17].

An increase in total serum lgE levels is observed with the use of omalizumab. However, we did not find any studies in the literature that demonstrate whether it has any effect on other immunoglobulins. According to the literature, it had been used for more than 2 years in an asthmatic patient with common variable immunodeficiency and discontinued due to neutrophilia, but it was not specified whether there was a change in the immunoglobulin levels with treatment in this study [18]. In our study we compared pre- and post-12-week treatment immunoglobulin levels and found a significant increase in total IgE levels, in alignment with the literature. But there was no significant difference when IgA, IgM, and IgG levels were compared. With these results, we suggested that omalizumab treatment can be used also in patients with CSU whose pre-treatment other immunoglobulin levels are low.

In our study, we also compared eosinophil, neutrophil, lymphocyte and platelet levels obtained from preand post-12-week treatment whole blood parameters. We found a significant decrease in post-treatment neutrophil levels. Although there was a significant reduction in neutrophil counts, this reduction was within the normal reference range and we did not find any decrease in the level of neutropenia in any of the patients. In a case reported by Banh et al., mild neutrophilia had developed in an asthmatic patient who was on omalizumab treatment for more than 2 years and neutrophil count returned to normal one month after omalizumab treatment was discontinued [18]. However, in the study by Yalcin et al., a significant reduction in neutrophil levels after 12 months of treatment due to asthma-chronic obstructive pulmonary disease (COPD) overlap syndrome (ACOS) was also observed in patients who received omalizumab [19]. Similarly to the study by Yalcin et al., we observed a significant reduction in neutrophil counts after omalizumab treatment.

The role of neutrophils in chronic spontaneous urticaria is unclear. Mediators are released from endothelial and epithelial cells, and pre-synthesized and newly synthesized cytokines are released from mast cells and basophils during late reactions. The primary effector cells such as neutrophils, basophils, mast cells, eosinophils and other immune cells such as macrophages, T cells and natural killer (NK) cells are involved in late reactions [20]. A significant decrease in the neutrophil count due to the use of omalizumab observed both in our study and in the study by Yalcin et al. suggests that it might be one of the mechanisms of action of omalizumab treatment. Although no decrease in the neutropenia level was observed in our study, patients were followed closely for a possible side effect due to omalizumab use. A significant decrease has been shown in the number of eosinophils after omalizumab treatment in patients with asthma [21, 22]. However, no significant change in eosinophil counts was observed in our study. We considered this as possibly related to the fact that our patients had CSU, not asthma.

In the evaluation of patients for response to treatment based on UAS-7, there was a complete response in $17(41.4 \%)$ patients and a significant response in 21 (51.2\%) patients, while there was no significant response in $3(7.31 \%)$ patients. Due to the lower number of patients without a significant response, patients were divided into two groups as patients with a complete response (41.4\%) and without a complete response (58.6\%), and baseline immunoglobulin levels and baseline eosinophils, neutrophil, lymphocytes and platelet levels were compared. No significant difference was found.

\section{Conclusions}

Omalizumab treatment increases serum IgE levels but has no effect on immunoglobulin levels. Omalizumab treatment can be used in patients with immunoglobulin deficiency when deemed necessary. Reduced blood neutrophil counts related to omalizumab use were observed, therefore patients must be closely followed for whole blood parameters.

\section{Conflict of interest}

The authors declare no conflict of interest.

\section{References}

1. Zuberbier T, Aberer W, Asero R, et al. The EAACI/GA(2)LEN/ EDF/WAO Guideline for the definition, classification, diagnosis, and management of urticaria: the 2013 revision and update. Allergy 2014; 69: 868-87.

2. Holgate ST, Djukanovic R, Casale T, Bousquet J. Anti-immunoglobulin $\mathrm{E}$ treatment with omalizumab in allergic diseases: an update on anti inflammatory activity and clinical efficacy. Clin Exp Allergy 2005; 35: 408-16.

3. Julia Eckl-Dorna. Omalizumab's impact on total and allergen-specific IgE levels: a polyclonal story. Int Arch Allergy Immunol 2016; 169: 69-70.

4. Ota T, Aoki-Ota M, Duong BH, Nemazee D. Suppression of IgE B cells and IgE binding to FcepsilonRI by gene therapy with single-chain anti- IgE. J Immunol 2009; 182: 8110-7.

5. Chu SY, Horton HM, Pong E, et al. Reduction of total IgE by targeted coengagement of IgE B-cell receptor and Fcgam- 
maRIlb with Fc-engineered antibody. J Allergy Clin Immunol 2012; 129: 1102-15.

6. MacGlashan DW Jr, Bochner BS, Adelman DC, et al. Downregulation of FcepsilonRI expression on human basophils during in vivo treatment of atopic patients with anti-IgE antibody. J Immunol 1997; 158: 1438-45.

7. Saini SS, MacGlashan DW Jr, Sterbinsky SA, et al. Down-regulation of human basophil IgE and FC epsilon RI alpha surface densities and mediator release by anti-lgE-infusions is reversible in vitro and in vivo. I Immunol 1999; 162: 5624-30.

8. Xolair Prescribing Information 2014.

9. Kaplan A, Ledford D, Ashby M, et al. Omalizumab in patients with symptomatic chronic idiopathic/spontaneous urticaria despite standard combination therapy. J Allergy Clin Immunol 2013; 132: 101-9.

10. Maurer M, Rosen K, Hsieh HJ, et al. Omalizumab for the treatment of chronic idiopathic or spontaneous urticaria. N Engl J Med 2013; 368: 924-35.

11. Saini SS, Bindslev-Jensen C, Maurer M, et al. Efficacy and safety of omalizumab in patients with chronic idiopathic/ spontaneous urticaria who remain symptomatic on $\mathrm{H} 1$ antihistamines: a randomized, placebo-controlled study. J Invest Dermatol 2015; 135: 67-75.

12. Metz M, Ohanyan T, Church MK, Maurer M. Omalizumab is an effective and rapidly acting therapy in difficult-totreat chronic urticaria: a retrospective clinical analysis. J Dermatol Sci 2014; 73: 57-62.

13. Presta LG, Lahr SJ, Shields RL, et al. Humanization of an antibody directed against IgE. J Immunol 1993; 151: 2623-32.

14. Shields RL, Whether WR, Zioncheck K, et al. Inhibition of allergic reactions with antibodies to IgE. Int Arch Allergy Immunol 1995; 107: 308-12.

15. Schroeder JT, Bieneman AP, Chichester KL, et al. Decreases in human dendritic celldependent $\mathrm{T}(\mathrm{H}) 2$-like responses after acute in vivo IgE neutralization. J Allergy Clin Immunol 2010; 125: 896-901.

16. MacGlashan D Jr, Xia HZ, Schwartz LB, Gong J. IgE-regulated loss, not IgE-regulated synthesis, controls expression of FCeRI in human basophils. J Leukoc Biol 2001; 70: 207-18.

17. Prussin C, Griffith DT, Boesel KM, et al. Omalizumab treatment down regulates dendritic cell FcepsilonRI expression. J Allergy Clin Immunol 2003; 112: 1147-54.

18. Banh HL, Trevoy J, Pabst H, et al. Persistent elevation of peripheral blood myeloid cell counts associated with omalizumab therapy. Am J Health Syst Pharm 2012; 69: 302-6.

19. Yalıın AD, Celik B, Yalçın AN. Omalizumab (anti-lgE) therapy in the asthma-COPD overlap syndrome (ACOS) and its effects on circulating cytokine levels. Immunopharmacol Immunotoxicol 2016; 38: 253-6.

20. Davies DE, Wicks J, Powell RM, et al. Airway remodeling in asthma: new insights. J Allergy Clin Immunol 2003; 111: 215-25.

21. Petsky HL, Kynaston JA, Turner C, et al. Tailored interventions based on sputum eosinophils versus clinical symptoms for asthma in children and adults. Cochrane Database Syst Rev 2007; 18: CD005603.

22. Green RH, Brightling CE, McKenna S, et al. Asthma exacerbations and sputum eosinophil counts: a randomised controlled trial. Lancet 2002; 360: 1715-21. 